\title{
Photopatch testing with an extended series of photoallergens: a 5-year study
}

\author{
José Carlos Cardoso, Maria Miguel Canelas, Margarida Gonçalo and Américo Figueiredo \\ Dermatology Department, University Hospital of Coimbra, Coimbra, Portugal
}

Objective: We conducted a retrospective study (2003-07) evaluating the results of photopatch tests (PPTs) performed with an extended series with the objective of determining the main photoallergens in our region and whether they would be detected by a recently recommended baseline PPT series.

Materials and methods: 83 patients (58 females/25 males, mean age 54.8 years) were tested with a photoallergen series, and among these, 30 were also tested with a non-steroidal anti-inflammatory drug (NSAID) series, irradiated at D2 with $5 \mathrm{~J} / \mathrm{cm}^{2}$ ultraviolet A (UVA).

Results: Thirty-six of 83 patients $(43.3 \%)$ had at least one positive reaction, with $21(25.3 \%)$ reacting in the photoallergen series. The main relevant reactions were as follows: 10 to ultraviolet filters (benzophenone- 3 and benzophenone-4, 3 patients each), 7 to promethazine, and 2 to chlorpromazine. Twenty of 30 patients tested $(70 \%)$ had a relevant positive PPT to an NSAID, 9 to piroxicam because of systemic photosensitivity, 8 to benzydamine from a topical gel or oral solution, and 2 to ketoprofen.

Conclusions: Our results are discordant with most recently published studies because of the particularities of the population studied and to regional prescribing habits. Therefore, apart from the recommended baseline series of photoallergens, other substances must be tested according to regional peculiarities.

Key words: drugs; photoallergens; photoallergic contact dermatitis; photopatch tests; systemic photosensitivity. (c) 2009 John Wiley \& Sons A/S.

Conflicts of interest: The authors have declared no conflicts.

Accepted for publication 17 February 2009

It is generally accepted that photoallergic contact dermatitis is uncommon, although its exact incidence is unknown (1-4). At least in part, this could be because of the underuse of photopatch testing as a diagnostic tool. The lack of standardization may contribute to this as well as the fact that photopatch testing stands between two areas of dermatology subspecializations: photodermatology and contact dermatology (1). To overcome this issue, the European Task Force for Photopatch Testing in 2004 proposed a consensus methodology for Europe (1). In this paper, a baseline series including only sunscreens and four non-steroidal anti-inflammatory drugs (NSAIDs) was defined, although the authors recognize that other agents should be considered according to variations in prescribing habits in different parts of Europe, particularly the topical NSAIDs and other less reported agents. It is also necessary to highlight that the use of some allergens will decrease, while others gain importance because of activities within the pharmaceutical and cosmetic industries. The use of photopatch testing should be encouraged in order to recognize these variations, allowing the inclusion of new substances with probable increasing importance and the withdrawal of older ones from testing series.

To understand the main photoallergens in our region of Portugal, we retrospectively evaluated the results of photopatch tests (PPTs) performed during 5 years using an extended series of photoallergens. 


\section{Patients and Methods}

Between 2003 and 2007, 83 patients ( 58 females/ 25 males, mean age 54.8 years) with suspected photoaggravated facial dermatitis or systemic photosensitivity were studied. All patients were patch tested with the European baseline series and photopatch tested with an extended series of photoallergens and, when appropriate, with their own products. Among them, 30 patients (18 females/12 males, mean age 61.0 years) were also photopatch tested with an NSAID series. The series of photoallergens included among 30 substances, 11 sunscreens, 8 salicylanilides and other antiseptics, and 5 drugs, including 2 phenothiazines (Table 1). Allergens were purchased from Trolab (Hermal, Reinbeck, Germany) or Chemotechnique Diagnostics (Vellinge, Sweden).

The NSAID series included four oxicams [piroxicam at $1 \%$ petrolatum (pet.) and tenoxicam, meloxicam, and lornoxicam all at 5\% pet.], three arylpropionic acid derivatives (ketoprofen 1\% pet., naproxen $10 \%$ pet., and ibuprofen $5 \%$ pet.), acetylsalicylic acid and diclofenac at $10 \%$ pet., and nimesulide and benzydamine at $5 \%$ pet. (Table 2 ). Allergens for the NSAID series were obtained from Chemotechnique Diagnostics, or pure substances supplied by the pharmaceutical industry were prepared at our hospital.

PPTs were performed according to the recommendations of the European Task Force on photopatch testing (1): briefly, allergens in Finn Chambers $^{\mathbb{R}}$ on Scanpor ${ }^{\mathrm{TM}}$ (Epitest Ltd Oy, Tuusula, Finland) were applied in duplicate on the back, one set was irradiated on D2 with $5 \mathrm{~J} / \mathrm{cm}^{2}$ ultraviolet A (Waldman $7001 \mathrm{~K}$, Medizintechnik, Schwenningen, Germany), and readings were performed at D2, before and $30 \mathrm{~min}$ after irradiation, and at D4. Only positive reactions (+ or greater, International Contact Dermatitis Research Group grading criteria) occurring exclusively on the irradiated set of allergens were considered, and their relevance was evaluated.

\section{Results}

Thirty-six of 83 patients $(43.3 \%)$ had at least one positive PPT in a total of 55 positive PPTs (6 of them to their own products).

Twenty-one patients $(25.3 \%)$ showed 28 positive PPTs in the photoallergen series (Table 3), most reactions with current or past relevance: 13 PPTs in 10 patients were because of ultraviolet (UV) filters (benzophenone- 3 and benzophenone- 4 in 3 patients each) related to the use of sunscreens or other cosmetics, 9 PPTs to phenothiazines occurred in 7 patients related to the use of Fenergan ${ }^{\mathbb{R}}$ cream (Vitória Laboratories, Amadora, Portugal) (con- taining promethazine and coumarin) and in 2 because of handling chlorpromazine pills.

Twenty-one of the 30 patients $(70 \%)$ tested had a relevant positive PPT to an NSAID (Table 4), 6 of them also with a PPT in the photoallergen series, considered either non-relevant or with a past relevance. Nine PPTs to piroxicam were because of systemic photosensitivity and were associated, in all patients, with positive patch tests to thiomersal and thiosalicylic acid tested at $0.1 \%$ pet. in the baseline series and negative PPTs to the other oxicams. Photoallergic contact dermatitis from benzydamine occurred in eight patients, in one with facial, forearm, and hand dermatitis because of regular application of a topical gel (Momen gel ${ }^{\circledR}$, Lepori Laboratories, Lisbon, Portugal) on his wife, and seven patients with facial dermatitis involving mainly the chin and lower lip because of regular gargling with oral antiseptic and anti-inflammatory oral solution (Tantum verde ${ }^{\mathrm{R}}$, Lepori Laboratories, Lisbon, Portugal). We observed two PPTs to ketoprofen (one in a patient with systemic photosensitivity from fenofibrate) and one each to acetylsalicylic acid and diclofenac attributed to systemic photosensitivity.

\section{Conclusions}

Contrasting with most published studies on photopatch testing where UV filters are by far the most frequent photoallergens (2-6), in our population, drugs (phenothiazines and NSAIDs) were responsible for $80.5 \%$ of the documented cases of photosensitivity ( 29 of the 36 reactive patients), reflecting the particular characteristics of our population and their use of drugs, some of which are not in the market of other European countries.

PPTs to UV filters were observed in 10 patients $(12.0 \%$ of the patients tested and $27.8 \%$ of reactive patients) and were responsible for $23.6 \%$ of the positive PPTs, with the benzophenones at the top, as in most recent studies; para-aminobenzoic acid (PABA) has been largely replaced, and isopropyl dibenzoylmethane is not used in Europe (2-7).

We stress the high reactivity to phenothiazines, particularly to promethazine that is still widely prescribed by family physicians and used as an overthe-counter antipruritic cream. This photosensitizer was frequently found in the 90s in Europe $(4,7)$, even though some PPTs could have been phototoxic reactions because of the high concentration of the test material available then $(1 \%$ pet.). Our reactions occurred with the low concentration $(0.1 \%$ pet.) and were relevant, as in a recent study from Greece (8). Because of its high phototoxic and photosensitizing potential, this drug should be removed from the market, as has already 


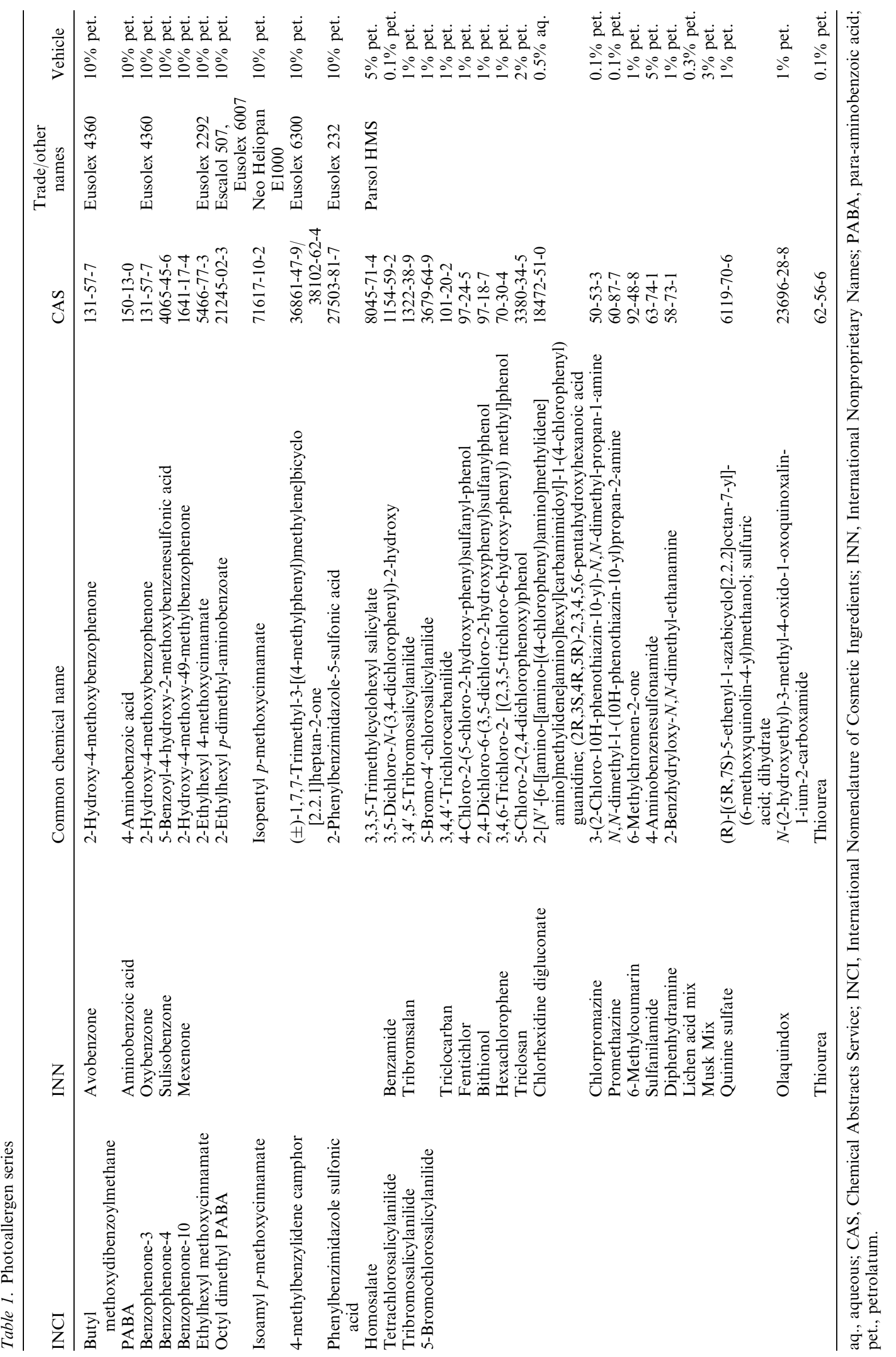




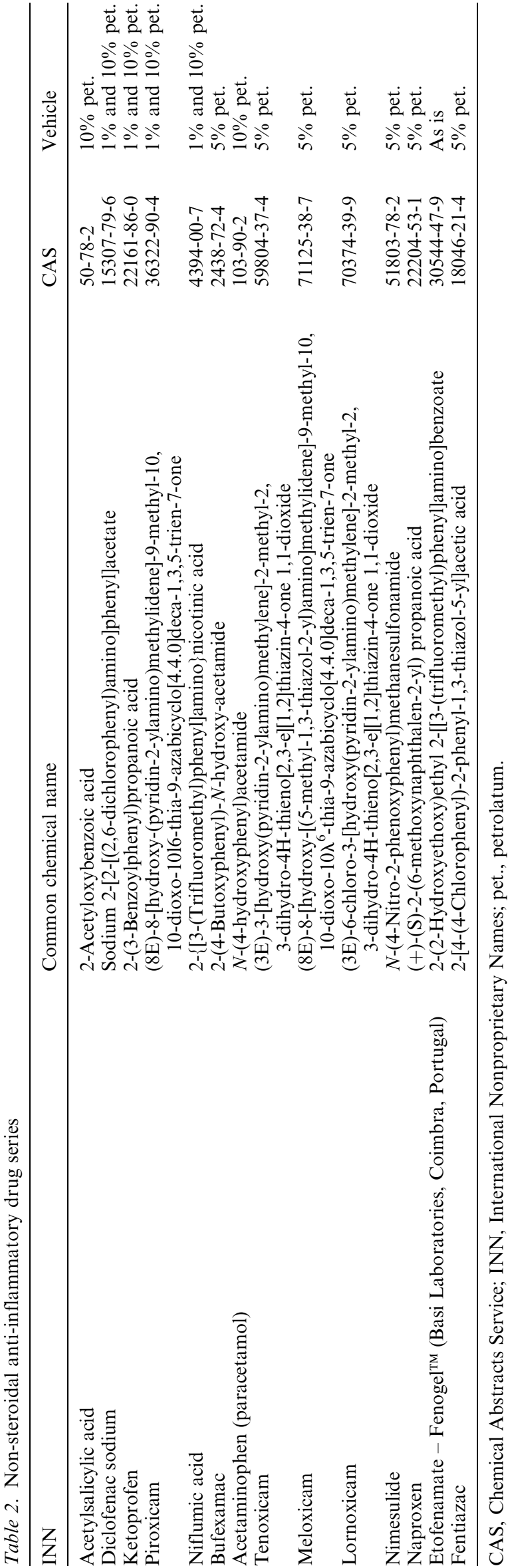

Table 3. Positive tests in the photoallergen series (patients tested: 83 )

\begin{tabular}{|c|c|}
\hline Allergens & $\begin{array}{l}\text { Positive } \\
\text { PPTs }\end{array}$ \\
\hline Promethazine $0.1 \%$ pet. & 7 \\
\hline Benzophenone-4 (sulisobenzone) $10 \%$ pet. & 3 \\
\hline Benzophenone-3 (oxybenzone) 10\% pet. & 3 \\
\hline 6-Methylcoumarin $1 \%$ pet. & 2 \\
\hline Chlorpromazine $0.1 \%$ pet. & 2 \\
\hline 4-Methylbenzylidene camphor $10 \%$ pet. & 1 \\
\hline $\begin{array}{l}\text { Butyl methoxydibenzoylmethane } \\
\text { (avobenzone) } 10 \% \text { pet. }\end{array}$ & 1 \\
\hline PABA (aminobenzoic acid) $10 \%$ pet. & 1 \\
\hline Ethylhexyl methoxycinnamate $10 \%$ pet. & 1 \\
\hline Isoamyl $p$-methoxycinnamate $10 \%$ pet. & 1 \\
\hline $\begin{array}{l}\text { Phenylbenzimidazole sulfonic } \\
\text { acid } 10 \% \text { pet. }\end{array}$ & 1 \\
\hline Benzophenone-10 (mexenone) $2 \%$ pet. & 1 \\
\hline Lichen acid mix $0.3 \%$ pet. & 1 \\
\hline Fentichlor $1 \%$ pet. & 1 \\
\hline Triclosan $2 \%$ pet. & 1 \\
\hline Phenofibrate pill $5 / 10 \%$ pet. $\left(\right.$ Catalip $\left.^{\mathbb{R}}\right)$ & 1 \\
\hline Fenergan cream $^{\mathbb{B}}$, as is & 3 \\
\hline Anthelios ${ }^{\mathbb{R}} \mathrm{XL}$ cream, as is & 1 \\
\hline Avon Illuminating Eye Color, as is & 1 \\
\hline Total of PPTs & 33 \\
\hline Total of reactive patients & 21 \\
\hline
\end{tabular}

PABA, para-aminobenzoic acid; pet., petrolatum; PPTs, photopatch tests.

happened in France with its analogue chlorproethazine contained in Neuriplege ${ }^{\mathrm{TM}}$ cream (Genevrier, Antibes, France) that was shown to be phototoxic and photoallergic $(7,9,10)$.

Concerning NSAIDs and contrasting the high frequency of photosensitivity from topical ketoprofen observed in Spain, Belgium, and Sweden $(6,11-14)$, we had only one case of photoallergic contact dermatitis to topical ketoprofen, a product that is seldom used in Portugal. The other positive PPT to ketoprofen occurred in a patient with systemic photosensitivity from fenofibrate (Cata$\operatorname{lip}^{\circledR}$, Fournier, Lisbon, Portugal) with a positive PPT to the powder of the pill and was attributed to cross-reactivity between these two molecules

Table 4. Positive tests in the non-steroidal anti-inflammatory drug series (patients tested: 30 )

\begin{tabular}{lc}
\hline Allergens & $\begin{array}{c}\text { Positive } \\
\text { PPTs }\end{array}$ \\
\hline Piroxicam $1 \%$ pet. & 9 \\
Benzydamine $5 \%$ pet. & 8 \\
Ketoprofen $1 \%$ pet. & 2 \\
Diclofenac $10 \%$ pet. & 1 \\
Acetylsalicylic acid $10 \%$ pet. $^{\circledR}$ Fenogel ${ }^{\mathbb{2}}$ (etofenamate) as is & 1 \\
Total of PPTs $_{\text {Total of reactive patients }}$ & 1 \\
\end{tabular}

Pet., petrolatum; PPTs, photopatch tests. 
that share a common benzophenone structure (15). Piroxicam, used systemically, remains the most common NSAID inducing photosensitivity reactions; we think that this is because of its frequent use in our region and also to the high prevalence of contact sensitization to thiomersal and thiosalicylic acid among our population (compounds that are frequent cause of cross-reactions with piroxicam) (16). As in previous studies, no cross-reactions were observed with the other oxicams (17). Benzydamine was frequently responsible for photoallergic contact dermatitis (eight cases), as in Spanish studies (6), but photoallergic contact dermatitis presented mainly as a lower lip and chin dermatitis, which is not a usual presentation for a photosensitive reaction (18).

Bruynzeel et al. (1), as already mentioned, proposed a baseline PPT series to be used in Europe and highlighted the importance of including other agents according to regional differences. The results of our study underline the importance of this recommendation: if we had used only UV filters and the four recommended NSAIDs, we would have missed relevant reactions in 19 patients, representing $52.8 \%$ of the patients who had positive PPTs.

\section{References}

1. Bruynzeel D P, Ferguson J, Andersen K et al. Photopatch testing: a consensus methodology for Europe. J Eur Acad Dermatol Venereol 2004: 18: 679-682.

2. Bryden A M, Moseley H, Ibbotson S H et al. Photopatch testing of 1155 patients: results of the U.K. multicentre photopatch study group. Br J Dermatol 2006: 155: 737-747.

3. Darvay A, White I R, Rycroft R J G, Jones A B, Haek J L M, McFadden J P. Photoallergic contact dermatitis is uncommon. Br J Dermatol 2001: 145: 597-601.

4. Bakkum R S, Heule F. Results of photpatch testing in Rotterdam during a 10-year period. Br J Dermatol 2002: 146: 275-279.

5. Schauder S, Ippen H. Contact and photocontact dermatitis to sunscreens: review of a 15-year experience and of the literature. Contact Dermatitis 1997: 37: 221-232.

6. Cuadra-Oyanguren J, Pérez-Ferriols A, Lecha-Carrelero M, Giménez-Arnau A M, Fernández-Redondo V, Ortiz de Frutos F J, Silvestre-Salvador J F, Serra-Baldrich E. Results and assessment of photopatch testing in Spain: towards a new standard set of photoallergens. Actas Dermosifiliogr 2006: 98: 96-101.
7. Leonard F, Adamski H, Bonnevalle A et al. Étude prospective multicentrique 1991-2001 de la batterie standard des photopatch-tests de la Société Française de Photodermatologie. Ann Dermatol Venereol 2005: 132: 313-320.

8. Katsarou A, Makris M, Zarafonitis G, Lagogianni E, Gregoriou S, Kalogeromitros D. Photoallergic contact dermatitis: the 15-year experience of a tertiary reference center in a sunny Mediterranean city. Int J Immunopathol Pharmacol 2008: 21: 725-727.

9. Barbaud A, Collet E, Martin S, Granel F, Trechot P, Lambert D, Schmutz J L. Contact sensitization to chlorproéthazine can induce persistent light reaction and crossphotoreactions to other phenothiazines. Contact Dermatitis 2001: 44: 373

10. Kerr A, Woods J, Ferguson J. Photocontact allergic and phototoxic studies of chlorproethazine. Photodermatol Photoimmunol Photomed 2008: 24: 11-15.

11. Diaz R -L, Gardeazabal J, Manrique P, Ratón J, Urrutia I, Rodriguéz-Sasiain J, Aguirre G. Greater allergenicity of topical ketoprofen in contact dermatitis confirmed by use. Contact Dermatitis 2006: 54: 236-243.

12. Mathieu L, Meuleman L, Van Hecke E, Blondeel B, Dezfoulian B, Constandt L, Goossens A. Contact and photocontact allergy to ketoprofen. The Belgian experience. Contact Dermatitis 2004: 50: 238-241.

13. Devleeschouwer V, Roelandts R, Garmyn M, Goossens A. Allergic and photoallergic contact dermatitis from ketoprofen: results of (photo) patch testing and follow-up of 42 patients. Contact Dermatitis 2008: 58: 159-166.

14. Hindsén M, Zimerson E, Bruze M. Photoallergic contact dermatitis from ketoprofen in southern Sweden. Contact Dermatitis 2006: 54: 150-157.

15. Durbize E, Vigan M, Puzenat E et al. Spectrum of crossphotosensitization in 18 consecutive patients with contact photoallergy to ketoprofen: associated photoallergies to non-benzophenone-containing molecules. Contact Dermatitis 2003: 48: 144-149.

16. Gonçalo M, Figueiredo A, Gonçalo S. Hypersensitivity to thimerosal. The sensitizing moiety. Contact Dermatitis 1996: 34: 201-203.

17. Serra D, Gonçalo M, Figueiredo A. Two decades of cutaneous adverse drug reactions from piroxicam. Contact Dermatitis 2008: 58: 35 .

18. Canelas M M, Gonçalo M, Figueiredo A. Photocontact dermatitis from benzydamine in 8 patients. Contact Dermatitis 2008: 58: 22-23.

Address:

José Carlos Cardoso

Serviço de Dermatologia

Hospitais da Universidade de Coimbra

Praceta Mota Pinto

3000-075 Coimbra

Portugal

Tel: +351239400420

Fax: +351239400490

e-mail: ze_carlos_cardoso@yahoo.com.br 